\title{
Linear System Representations
}

\author{
J.M. Schumacher \\ Centre for Mathematics and Computer Science (CWI) \\ Kruislaan 413, 1098 SJ Amsterdam, the Netherlands \\ and \\ Department of Economics, Tilburg University \\ P. O. Box 90153,5000 LE Tilburg, the Netherlands
}

\section{INTRODUCTION}

The theory of system representations is concerned with the various ways in which a 'system' (a dynamical relation betwecn several variables) can be described in mathematical terms. This paper will concentrate on the class of linear, time-invariant, detcrministic, finitc-dimensional systems, for which there exists indecd a variety of representations. The study of system representations is of interest for two reasons, which correspond to two different points of view. First of all, even when representation types (or 'model classes') are mathematically cquivalent, the casc with which a particular problem is handled may be quite representation-dependent. Also, it may happen for instance that a problem is best understood theorctically in onc representation, but that another representation is most uscful for the numcrical solution. Thus, onc should bc ablc to switch from one representation to another. The study of the corresponding transformations belongs to representation theory. The second reason for interest in system representations is connected with the modcling prohl $/ \mathrm{m}$. Often, a model for a physical system is built up by writing down cquations for the components and for the connection constraints. In this way, onc obtains a system representation. It may be uscful, though, to rewrite the equations; the derivation of the Euler-Lagrange cquations of mechanics could be citcd as an example. Again, we have here a problem of transformation between system representations.

Interest in the theory of system representations has been stimulated in recent years by a scrics of papers by J.C. Willems $[64,68-70,72,73]$. In this work, the 'modeling' point of vicw has becn cmphasized. As noted by Willems, cven such raw data as an obscrved time scrics can already be taken as a system representation, and the identification problem then becomes a problem of transformation of representations. In this paper, we shall concentrate on representations by cquations rather than by measured data. A survey of system representations and transformations will be presented in the spirit of $[71]$. We shall use the notion of 'external cquivalence', again following 
Willcms.

The next section contains a bricf historical survey of system representations in conncetion with control theory, centered on the description of linear, finite-dimensional, deterministic systems. After that, we shall attempt to give an up-to-date account of the results concerning the representation of this class under external cquivalence. Section 4 will be devoted to an application of the theory to the idea of a factor system, and the paper will be closed with conclusions and rescarch perspectives.

\section{SYSTEM REPRESENTATIONS: A HISTORICAL SKETCH}

The birth of mathematical control theory is often dated 1868, the year of the publication of J.C. Maxwcll's paper "On Governors" [42]. In this paper, Maxwell deals with a number of contrivances that in his time were in use to regulate the opcration of steam engines. Maxwell uses sccond order equations to describe the motions of the engine itself and the regulators. He takes the coupling of the different parts into account and lincarizes to obtain a coupled sct of sccondorder linear differential equations. As an cxample, the following equations appear for a stcam engine regulated by a combination of 'Thomson's governor with Jenkin's governor (in Maxwell's notation):

$$
\begin{aligned}
A \frac{d^{2} \theta}{d t^{2}}+X \frac{d \theta}{d t}+K \frac{d \phi}{d t}+T \phi+J \psi & =P-R \\
B \frac{d^{2} \phi}{d t^{2}}+Y \frac{d \phi}{d t}-K \frac{d \theta}{d t} & =0 \\
C \frac{d^{2} \psi}{d t^{2}}+Z \frac{d \psi}{d t}-T \phi & =0 .
\end{aligned}
$$

Herc, $P-R$ denotes the effective driving torque. The main variable is $\theta$, which represents the deviation of the main shaft angle from its nominal valuc. The variables $\phi$ and $\psi$ correspond to the two governors. Maxwell then writes the gencral solution for 0 , which, by the standard theory of ordinary differential cquations, involves a lincar combination of exponential functions. These exponential functions are determined by the roots of a polynomial equation that can be derived readily from the given system. Maxwcll writes $n$ for the unknown, and obtains a fifth-degrec cquation by sctting

$$
\left|\begin{array}{ccc}
A n^{2}+X n & K n+T & J \\
-K & B n+Y & 0 \\
0 & -T & C n^{2}+Z n
\end{array}\right|=0
$$

(a factor $n$ has been cancelled right away in the second row). He is then confronted with the prob$\mathrm{lcm}$ of determining conditions on the coefficients under which all solutions of this cquation are located in the left half of the complex plane. This, of course, led to the work of Routh on conditions for the stability of polynomials of arbitrary degrec. We sec that Maxwcll's fifth-order equation arises from the application of a fourth-order controller to a second-order system, and that the conditions for stability are given by him in terms of the zcros of a polynomial matrix that is obtaincd dircetly from a standard modeling procedurc.

Maxwell used second-order differential equations, but it gradually became standard in the ninetecnth century to write differential cquations in first-order form. The fact that a higher-order differential equation in one variable may be replaced by a first-order equation in several variables 
was actually alrcady known in Cauchy's time. The Lagrangian cquations of mechanics were later put into a suitable first-order form by llamilton; towards the end of the century, Poincare and Lyapunov used first-order vector representations systematically. Naturally, therefore, representations of this type (called state representations later on) have dominated control-theoretical work that was done in close connection with the theory of ordinary differential equations. This concerned mainly lincar stability theory at first, but later, in the first decades of the twentieth century, attention shifted to nonlinear problems. This line of rescarch was held up high especially in the USSR (sce for instance the survey by Minorsky in [45]).

The work in connection with differential equations had a natural tendency to emphasize closed-loop systems, obtained by combining a given system with a given controller. Indecd, for such systems one may readily apply the powerful methods from the theory of ordinary differential cquations and allicd disciplines, such as the theory of differential-difference (delay) cquations. The analysis by Maxwell, as bricfly described above, is an cxample of this approach. The closed-loop point of vicw is quite satisfactory for many problems in mechanical enginecring. To the communications enginecr, however, it is more natural to use an open-loop point of view, in which a system is viewed as an opcration that acts on an input signal and produces an output signal. This 'opcrational' point of view called for a representation which would express the output signal as the result of some opcrator acting on the input signal. Such a representation is provided, at least for lincar systems, by the convolution integral. Ilowever, competing representations were soon to appear. Inded, the use of complex quantitics for the representation of complex signals, the Fouricr and Laplace transforns, and Ileaviside's Operational Calculus were all in principle available by the turn of the century. The value of these techniques was gradually recognized among electrical cngincers, be it ccrtainly not without resistance (sce for instance [46]). I'rom the mathematical point of vicw, the use of operational methods led to the introduction of techniques quite different from the oncs usually found in the theory of differential cquations. Applications of complex function theory were limitcd at first to partial fraction expansions and computation of intcgrals, but the appearance of the Nyquist critcrion [47] made cngincers rcalize that full-fledged function theory was a natural tool to use in the analysis of lincar systems [10, p. 9]. Function-theoretic tools, in particular Cauchy's theorem, were used cxtensively by Bode in his book [9], which incorporated the celcbrated Bode gain-phase relation and the minimum phase concept. The development of the root locus method by Evans in 1948 [18] firmly cstablished the view of the transfer function as a function defined on the complex plane rather than just on the real frequency axis. For a more extensive discussion of the development of frequency-domain methods, we refer to [40]. We will not at all revicw the devclopments in the area of stochastic systems. In connection with what just has becn said, however, it is interesting to quote Wiencr on some of the differences between his own work and that of Kolmogorov:

... my work, unlike the explicitly published work of Kolmogoroff, concerns the instrumentation which is necessary to realize the theory of prediction in automatic apparatus for shooting ahcad of an airplanc. This engincering bias lcads me to cmphasize morc than docs Kolmogoroff the problem of prediction in terms of lincar operators in the scalc of frequency, rather than in similar operators on the scalc of time. [63, p. 308]

While the communication engincers developed their own methods, work on the ODE-type approach to control systens was still continuing, in particular in the Sovict Union. During the Second World War, a rescarch centre was formed in Kazan where work on applied problems was donc by outstanding mathematicians such as L.S. Pontryagin, who had alrcady acquired fame 
because of his pre-war contributions to topological algebra. After the war, research efforts in control theory continued at various mathematical institutes in the USSR. Onc important research direction centered around 'Aizcrman's conjecture' [1], a nonlinear generalization of the Nyquist critcrion. This problem called for a representation of systems with an explicitly appearing input variable, unlike the setting that was mainly used before in the 'ODE' framework. Systems with one input were studicd first, in line with the original work of Nyquist, but the extension to several inputs was a natural onc. For instance, Lctov [35] considered in 1953 the following systent (in original notation):

$$
\begin{aligned}
& \dot{\eta}_{k}=\sum_{\alpha=1}^{n} b_{k \alpha} \eta_{\alpha}+n_{k 1} \xi_{1}+n_{k 2} \xi_{2} \quad(k=1, \cdots, n), \\
& \dot{\xi}_{1}=f_{1}\left(\sigma_{1}\right), \quad \sigma_{1}=\sum_{\alpha=1}^{n} p_{1 \alpha} \eta_{\alpha}-r_{11} \xi_{1}-r_{12} \xi_{2}, \\
& \dot{\xi}_{2}=f_{2}\left(\sigma_{2}\right), \quad \sigma_{2}=\sum_{\alpha=1}^{n} p_{2 \alpha} \eta_{\alpha}-r_{21} \xi_{1}-r_{22} \xi_{2} .
\end{aligned}
$$

We recognize the first cquation (with hindsight, perhaps) as a linear state cquation with two inputs.

The carly fiftics saw the rise of modern optimal control theory. One of the first problems to be studicd was time-optimal control. In some applications, it is natural to consider control strategies in which one switches betwecn full power in one dircction and full power in the reverse direction. This motivated a study of dificrential cquations with discontinuous forcing terms by D. W. Bushaw at Princeton University [11]. Bushaw noted that the switching instant could be optimized to obtain a transfer from one state to another in minimal time. Subscquently, J.P. LaSalle observed that 'bang-bang' policics would be optimal among all possible control policics which lead from a given state to another. LaSalle used a nonlinear formulation, but later on Bcllman et al. considered lincar systems [7]. In this paper, Bellman and his co-authors requircd invertibility of the input matrix (as we would now call it), so in particular they let the number of inputs be eq"al to the number of states. In independent work, Gamkrelidze [25] considered shortest time problems for linear systems with $n$ states and $r$ inputs. He writes the following state cquation [25, p. 451]:

$$
\dot{\mathbf{x}}=A \mathbf{x}+\mathbf{b}_{1} u^{1}+\cdots+\mathbf{b}_{r} u^{r}
$$

which is practically the formula $\dot{x}=A x+B u$ that has become ubiquitous in control theory.

By the end of the fiftics, the time had come for an amplification of the notion of 'state' far bcyond its meaning as the vector that appears when dynamic cquations are written in a first-order form. This was duc to the rolc that this concept had to play in Bellman's dynamic programming method, but also to developments in the theory of automata (finite state machincs; Nerode cquivalcnce).

In control theory, the announcement by Pontryagin of his Maximum Principle at the International Mathematical Congress in Ldinburgh in 1958 had a tremendous impact on research in optimal control. Bang-bang control problems, in which one secks to stecr from one state to another, naturally led to the formulation of the concept of controllability by R. E. Kalman. This concept, and the dual notion of obscrvability, turned out to play a crucial role in what Kalman called the realization problem: 
Given an (experimentally observed) impulse response matrix, how can we identify the linear dynamical system which generated it? [30, p. 153]

The word 'realization' is uscd here in a scnse that is different from the traditional usage in clectrical enginccring. There, one would look for realization of a given driving-point impedance as an actual or idcalized clectrical circuit (cf. also the use of the term 'rcalize' in the quotation from Wiencr given above). Although Kalman did advertize the state space realization as a 'blueprint' which could serve as a basis for implementation in an analog network [28], this connection was hardly cmphasized in subsequent tescarch.

In the ncwly founded SIAM Journal on Control, E. Gilbert argued that the transfer represcntation was mislcading and could Icad to crroncous results. His point was that unobservable and/or uncontrollable states could be created by system composition:

Thus transfer-function matrices may satisfactorily represent all the dynamic modes of the subsystems but fail to represent all those of the composite system. Furthermore, the loss of hidden response modes is not casy to detect because of the complexity of the transfer-function matrices and matrix algcbra. [27, p. 140]

To develop lincar control theory from the statc space point of vicw, it had to be shown that the familiar concepts from the frequency domain could be translated to state space terms. For this, the ncw realization theory was an indispensible tool. Gilbert [27] used partial fraction expansion (much in the tradition of Heaviside, onc might say) to obtain a statc space realization for a transfer matrix having only simple polcs. This method can be extended to the general situation (not necessarily simple poles), but then becomes somewhat involved (sce [50]). A morc elegant rcalization algorithm was published by Kalman and B. L. Ho in 1966 [28]. The algorithm was based on a new parametrization of the transfer matrix - new at lcast to control theory: in 1894, A. A. Markov had alrcady used csscntially the same parametrization for a study of continucd fractions [41]. The 'Markov parancters' are the first (matrix) cocfficients in the power scrics devclopment around infinity of a proper rational matrix.

Ior a whilc, 'realization theory' was, at Icast to the system theorist, practically cquivalent to the determination of a state space represcntation from a transfer matrix given through its Markov parametcrs. The seventics, however, brought a renewed interest in polynomial representations. An important impctus for this devclopment came from the appearence of Roscnbrock's book [51] on multivariable systems. In this work, Rosenbrock considered input/output systems given in the form

$$
\begin{aligned}
T(s) \xi & =U(s) u \\
y & =V(s) \xi+W(s) u
\end{aligned}
$$

where all matrices are polynomial. Great cmphasis was placed on the study of equivalence notions. Roscnbrock found a 'lifting' of Kalman's system cquivalence roncept to the more gencral representation displayed above, which he called strict system equivalence. It secms safe to say that the systematic development of the theory of system representations, system cquivalence and system transformations starts with [51].

From Rosenbrock's system matrix, the transfer matrix is represented as $V(s) T^{1}(s) U(s)+W(s)$, i.c., as a ratio of polynomial matrices. It is not difficult to sec that, in fact, cvery rational matrix can be written in either of the two forms $V(s) T{ }^{1}(s)$ or $T^{1}(s) U(s)$, where, morcover, a coprimeness condition may be imposed. Thesc coprime fractional representa- 
tions werc used very successfully by Kučera $[31,32]$ and by Youla et al. $[79,80]$ to give a parametrization of all stabilizing controllers for a given plant. This is an example of a result that appears quite naturally in one representation but would be awkward to derive in some other representations. At the same time, fractional matrix representations were also used in work on infinitedimensional realization problems done at Harvard University by R.W. Brockett, J.S. Baras, and P.A. Fuhrmann (sce for instance [6]). In the infinitc-dimensional context, the available mathematical tools strongly suggested to replace polynomials by functions analytic on the unit disk (in the discretc-time case - for continuous-time systens, the class to use would be the set of functions that are analytic on the right half plane). This idea was picked up by researchers in finitc-dimensional system theory, who discovered that some difficultics with the Kučera-Youla parametrization could be ironed out by using the ring of rational functions that have no poles in the closed right half plane (including the point at infinity) rather than the ring of polynomials (sce for instance [16]). The fractional representation over the ring of proper and stable rational functions was subscquently used cxtensivcly in the cmerging $\|^{\infty}$-theory, which is in itsclf an example of an application of function-theorctic techniques to control problcms in a way that would probably have been quite beyond the imagination of Nyquist and Bode. On the other hand, $H^{\infty}$. theory has also relied heavily on state space representations, since the representation in terms of constant matrices makes it possible to usc standard numerical softwarc. The cooperation betwecn the two represcntations was facilitated by the discovery (attributed to D. Aplevich in [62]) that there is an casy way to pass from a state space representation to a fractional representation over the ring of proper stable rational functions. (Fractional representations over the ring of polynomials cannot be obtaincd in a comparable way from a state space representation.)

Nevertheless, polynomial representations were cmphasized again in the mid-seventics when Fuhrmann worked out an clegant procedurc to go from a polynomial matrix fraction representation to a state space representation [23]. The discovery of this procedure, now known as Fuhrmann's realization, spurred considerable rescarch on the relation between state space concepts, as developed in particular in the 'geometric approach' to linear systems [77], and polynomial or transfer matrix concepts. For an introduction to this, sce for example Chapter 1 of [24].

Polynomial matrices, even when less suitable for a number of purposes than stable proper rational matrices, are important in system theory becausc they arisc naturally in modeling. Indecd, a polynomial matrix representation can be written down immediately from a set of lincar differential and algebraic equations describing a given system. Maxwell's cquations for the controlled stcam cngine, as given above, may serve as an example. Of course, by the old trick of replacing higher-order derivatives by new variables, it is also possible to obtain a first-order representation. Instead of the Rosenbrock form discussed above, one then gets a representation in the form

$$
\begin{aligned}
E \dot{x} & =A x+B u \\
y & =C x+D u,
\end{aligned}
$$

where $E, A, B, C$, and $D$ are constant matrices. The variable " $x$ " which appears here was called the descriptor variable by Luenberger, who was first to make an extensive study of this representation in system theory $[37,38]$. Contrary to the standard state space representation, the descriptor form is capable of representing systems having a non-proper transfer function (also called 'non-causal systems' or 'singular systems'). Through the years, the term 'descriptor system' has come to be used almost cxclusively for such systcms, although this was certainly not Luenberger's original 
intention - he was trying to cmphasize the modeling issuc, rather than the question of causality. The descriptor form was used by Verghese [60] to define an equivalence concept which deals neatly with polc/zero cancellations at infinity. This cleared up a problem which had remaincd unsolved in Rosenbrock's work. Alternative solutions were given later by Anderson, Coppel and Cullen [2] and by Pugh, Hayton and Fretwell $[48,49]$. The fact that the notions of cquivalence defined by these authors are indecd the same was established by Iicrreira [19]. Further conments on descriptor systems will be given in the next section.

In recent ycars, the study of system representations has been stimulated by the work of J.C. Willems. There are several important points where his approach is different from other approaches discussed above. First of all, Willems uses an intrinsic definition of system equivalence (i.c., onc that does not depend on a specific representation). Ile does this by defining a 'systen' simply as 'a family of trajectorics of given variables' (such as the port voltages and currents of an electrical network, or forces and displacenents in a mechanical system). The given variables which appear in the definition are also denoted as 'external variables', to distinguish them from 'internal variables' which are possibly used as auxiliary quantitics in a description of the system. The cxtcrnal variables may consist of what arc usually called 'inputs' and 'outputs', but, as shown in section 4 of this paper, other interpretations can sometimes also be uscful. The family of trajectorics is also referred to as a 'bchavior'

In this approach, there is some flexibility associated with the choice of the function space to which the trajectorics that make up the system arc supposed to belong. In the study of differential cquations, onc normally uscs function spaces that allow for exponentially growing solutions (such as $C^{\infty}$, or the space of distributions). In the context of system theory, however, it also makes sense to consider for instance only those trajectorics that are square integrable. Different choices of function spaces lead, in this way, to different notions of system; put in another way, they Icad to different equivalence relations on system descriptions. Morc on this will be said below. Willens has shown [68] that, if one interprets 'extcrnal variables' as 'inputs and outputs' and uses the classical function spaces alluded to above, the equivalence relation that cmerges is in fact different from the equivalence relations that were mentioned above.

It should be noted that the definition of a 'system' as a family of trajectorics is not new. Comparc, for instance, McMillan's definition of a $2 n$-polc:

The constraints imposed by a general $2 n$-pole $\mathrm{N}$ on voltages and currents are completcly described by the totality of pairs $[\underline{v}, \underline{k}]$ which $\mathrm{N}$ admits. We shall define a gencral $2 n$-polc, thercfore, as

(i) a collection of $n$ oriented idcal branches, as in 4.11 , and

(ii) a list of pairs $[\underline{v}, k]$ of voltages and currents admitted in these branches.

[44, p. 228]

(The oriented ideal branches in $\S 4.11$ of McMillan's paper scrve just to define the pairing of the terminals.) In recent work in system theory, the equivalence notion as used by Willems has in fact occurred in several places; sce [4, p. 513] ('cxternal equivalence') and [8, p. 92] ('input-output cquivalence'). Nevertheless, there is no doubt that the conscquences of the acceptance of this intrinsic definition of what a system is have becn explored to the fullest in the work of Jan WilIcms. 


\section{A ROAD MAP OF REPRESENTATIONS}

In this section, we shall review the available representations for a specific class of systems, viz.., the class of finitc-dimensional, deterministic, time-invariant, rcal, lincar systems in continuous time, without further special structurc. (The addition 'without further special structure' refers to the fact that we shall not consider special propertics that arise, for instance, for systems defined on a symplectic spacc.) This is the class that has scrved as sort of a standard in system theory during the last three decades, except that causality is often imposed as an additional requirement. This condition was not included in the list above for two reasons. Fïrst of all, we are sometimes interested in cxternal variables that are not to be considered as 'inputs' and 'outputs' (cf. Section 4 of this paper, for instance), and in such cascs causality need not be a relevant issuc. Secondly, even when we do distinguish inputs and outputs, there are no simple ways to tell, at a general lcvel of representation such as Rosenbrock's system matrix, whether a given system is causal or not [51, p. 51]. Imposing causality as a constraint on such gencral linear system representations would thereforc bc awkward.

\subsection{Notions of equivalence}

When discussing system representations, we will have to specify under which circumstances we shall say that two representations are cquivalent in the sense that they correspond to the same system. There are threc main options. There is the notion of strong equivalence, which boils down to Kalman's concept of cquivalence for causal input/output systems in standard statc space form. Definitions of this cquivalence (by specification of a list of allowed transformations) were given at the level of descriptor systenis by Verghese [60] and by Pugh et al. [48, 49], and by Anderson et al. at the level of the Rosenbrock system matrix [2]. Sccondly, for every class of representations that have a given input/output structure and that define a transfer matrix, one has the notion of transfer equivalence according to which two representations are equivalent if and only if they define the same transfer matrix. linally, if onc considers representations that define a family of trajectorics of the external variables (an 'external bchavior' in the sense of [68]), then there is the notion of external equivelence' according to which two representations are cquivalent if and only if they induce the same external behavior.

As noted before, extcrnal cquivalence can in fact be understood in various ways, depending on the choice of a function space for the trajectorics, and on the choice of external variables. There is also some frecdom that arises from the interpretation of the external variables. For example, if we allow only permutation transformations on the extcrnal variables, this means that these variables are interpreted as quantitics which each have there own meaning and are measured on a fixed scale. On the other hand, if we allow gencral invertible linear transformations, then the implication is that the vector of external variables is understood as an element of a general linear space. It gocs without saying that, depending on the problem one has at hand, some of the external variables can be interpreted in one way and others in another way. (The same might be said about the choice of a function space.) The term 'cxternal cquivalence' will be used for what might be called the 'classical' interpretation: the function space is such that exponentially growing solutions are admitted (we shall use $C^{\infty}$ to make life a little bit casier), and only permutation operations will be allowed on the cxternal variables. We call this the 'classical' form because it would secm that the notion of cquivalence that is used (often implicitly) in treatments of ordinary differential cquations is of this type. If onc uses an $L_{2}$-space rather than a $C^{\infty}$-space as a trajectory space, then (cf. [74]) the corresponding notion of external cquivalence turns out to be an cxtension of transfer equivalence, in the sense that it coincides with transfer cquivalence on the 
class of systems that define a transfer matrix. Suppose now that one has a systen of equations in the form

$$
\begin{aligned}
\sigma x & =A x+B u \\
y & =C x+D u .
\end{aligned}
$$

One might proposc to takc $u, y$, and $x$ as extcrnal variables following $C^{\infty}$-trajectorics, to interpret $u$ and $y$ ' in a 'classical' sense, and to interpret $x$ as a variable in a gencral linear spacc. The resulting concept of equivalence is Kalman's cquivalence. It may be suspected that a similar reinterpretation in terms of extcrnal cquivalence is also possible for strong equivalence.

To keep the presentation manageable, we shall consider transformations under 'classical' external equivalence. For other types of equivalence, the picture will be different but similar. We will discuss special representations for systems equipped with an i/o structure, but the particular representations that are available only for causal systems will be omitted.

\subsection{A catalog of representations}

We start by listing a number of representations. A number of basic types will be distinguished that are different by appearance; within these, we distinguish subtypes that do not differ notationally but that are subject to more or less severe constraints.

The most unspecific type of represcntations we shall takc into consideration is the AR/MA class. An AR/MA representation is specificd by two polynomial matrices $P(s)$ and $Q(s)$, which detcrmine the external bchavior consisting of all trajectorics $w$ of the external variables for which there cxists a trajectory $\xi$ of the internal variables such that

$$
\begin{aligned}
P(\sigma) \xi & =0 \\
w & =Q(\sigma) \xi .
\end{aligned}
$$

In the continuous-time interpretation we use here, $\sigma$ stands for $\mathrm{d} / \mathrm{d} t$. The class is called AR/MA because of the discretc-time interpretation in which $\sigma$ is the shift: in this case, (3.3) implics that the external variables are expressed as a moving average of the internal variables, which themselves satisfy an autoregressive cquation. Every representation of this kind can trivially be rewritten as a 'systenı with auxiliary variables' [68] (later also called an 'ARMA' representation by Willems [73]), which is defined by an equation of the form

$$
P^{\prime}(\sigma) \xi+Q^{\prime}(\sigma) w=0
$$

simply take

$$
P^{\prime}(s)=\left[\begin{array}{l}
P(s) \\
Q(s)
\end{array}\right], \quad Q^{\prime}(s)=\left[\begin{array}{c}
0 \\
-I
\end{array}\right] .
$$

On the other hand, it is also casy to write an AR/MA representation for a system with auxiliary variables, by extcnding the space of intcrnal varialiles and writing

$$
P(s)=\left[\begin{array}{ll}
P^{\prime}(s) & Q^{\prime}(s)
\end{array}\right], \quad Q(s)=\left[\begin{array}{ll}
0 & I
\end{array}\right] .
$$

We sec that the AR/MA representation is, in gencral, Icss parsimonious in the use of internal variables than the representation as a systcm with auxiliary variables. Since we arc looking for an unspecific represcntation, this might be construed as an argument against the representation in the form (3.4). Actually, when dealing with systems described by partial differential cquations, one casily runs into clcar-cut cascs in which an AR/MA representation appears much more naturally 
than a representation with auxiliary variables as in (3.4).

For systems with an i/o structure, another general representation is RSM (Rosenbrock system matrix [51]). An RSM representation is specificd by four polynomial matrices $T(s), U(s)$, $V(s), W(s)$, where $T(s)$ is square and invertible. The external belhavior defined by an RSM representation consists of the sct of all input trajctorics $u$ and output trajectories $y$ for which there exists an internal-variable trajectory $\xi$ such that the following cquations hold:

$$
\begin{aligned}
T(\sigma) \xi & =U(\sigma) u \\
y & =V(\sigma) \xi+W(\sigma) u .
\end{aligned}
$$

The third polynomial representation we shall consider is the AR representation [69]. An AR representation is specificd by a single polynomial matrix $R(s)$, which should have as many columns as there are external variables. The external behavior it defines is simply the set of all cxtcrnal-variable trajectorics $w$ satisfying

$$
R(\sigma)^{\prime}=0 .
$$

We shall always requirc $R(s)$ to have full row rank; this simply means that the equations specified by the rows of $R(s)$ are independent. An AR representation given by $R(s)$ will be said to be minimal if the sum of the row degrecs of $R(s)$ is minimal in the set of all AR representations of the same system. One can show (sce for instance $[69$, Thm. 6]) that a matrix $R(s)$ is minimal in this sense if and only if it is row proper. The class of minimal AR representations will be denoted by $A R_{\min }$. If the cxtcrnal variable is partitioned into inputs and outputs, the defining matrix $R(s)$ of an AR representation will be divided into two blocks $R_{1}(s)$ and $R_{2}(s)$, which correspond to outputs and inputs respectively. If $R_{1}(s)$ is square and nonsingular, the representation so obtaincd will be called an LMF representation ('Icft matrix fraction').

By introducing new internal variables, it is easy to transform an AR/MA representation to a first-order form

$$
\begin{aligned}
\sigma G \xi & =N \xi \\
w & =H \xi
\end{aligned}
$$

( $F, G$, and $H$ are constant matrices). This representation, specificd by the threc matrices $F, G$, and $H$, will be called the pencil representation ([33]; cf. also [4, 56]), and the corresponding class of representations will be denoted by $P$. To be complete, one should also indicate the spaces on which the various mappings are defined, and so we shall sometimes also give a $P$ representation as a sixtuple $(F, G, H: Z, X, W)$ where $F$ and $G$ are mappings from the 'internal variable space' $Z$ to the 'cquation space' $X$, and $H$ maps $Z$ into the external variable space $W$. A descending chain of subclasses can be formed by putting morc and more strict requirements on the triple $(F, G, H)$. If $G$ is surjective, the corresponding class will be denoted by $P_{d v}$, because this class is closely related to the DV representations that will be discussed below. The class of representations which in addition satisfy the condition that $\left[G^{\top} I^{\top}\right]^{\top}$ is injective will be denoted by $\mathrm{P}_{\mathrm{io}}$; in a representation of this type, onc can casily sce which partitionings of the external variables into inputs and outputs will lcad to a causal i/o structure (cf. [33], Lemma 5.1 and Lemma 6.1). Finally, pencil representa-

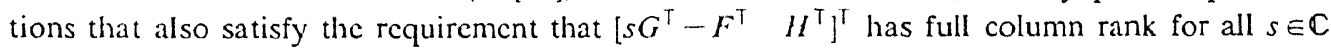
form a class that will be denoted by $P_{\text {mirl. }}$. It has been shown in [33] (Prop. 1.1) that a pencil representation is minimal under external equivalence if and only if it belongs to $P_{\min }$.

Next in our collection of representations is the DV (driving-variable) representation $[4,68,69,73]$, which, as already mentioned, is closely related to the $P_{d v}$ class. A DV representation 
is specificd by four constant matrices $A, B, C^{\prime}$, and $D^{\prime}$, which determinc an cxternal bchavior by the equations

$$
\begin{aligned}
& \sigma \xi=A \xi+B \eta \\
& w^{\prime}=C^{\prime} \xi+D^{\prime} \eta
\end{aligned}
$$

( $\xi$ and $\eta$ arc auxiliary variables). The class of DV representations for which the matrix $D^{\prime}$ is injective will be denoted by $D V_{\text {io }}$. If also the requirement is imposed that the 'system pencil'

$$
\left(\begin{array}{cc}
s I-A & B \\
C^{\prime} & D^{\prime}
\end{array}\right)
$$

has full column rank for all $s$, then we obtain a class of representations that will be denoted by $D V_{\text {min }}$. It has been shown in [68] that a $D V_{\text {min }}$ representation is minimal in the class of DV representations, in the sense that both the Iength of $\xi$ and the Iength of $\eta$ are minimal.

lor input/output behaviors, there are further special representations that may be used. A well-known form is the descriptor representation $[37,38]$. The class of such representations will be denoted by $D$. A descriptor representation is specificd by five constant matrices $E, A, B, C$, and $D$, and detcrmincs an input/output bchavior by the cquations

$$
\begin{aligned}
\sigma E \xi & =A \xi+B u \\
y & =C \xi+D u .
\end{aligned}
$$

The domain of the mappings $E$ and $A$ will be denoted by $X_{\mathrm{d}}$ (descriptor space), the codomain will he written as $X_{\mathrm{c}}$ (equation space).

Quitc a fcw special propertics have becn uscd in the literaturc in connection with this representation (sce for instance $[5,13,36,52,61,78]$. We shall use the following conditions. The represcntation (3.11) is said to be controllable at infinity. if

$$
\operatorname{im} E+\operatorname{im} B+A(\operatorname{kcr} E)=X_{\mathrm{c}} \text {. }
$$

It is said to be reachable at infinity if

$$
\operatorname{im} E+\operatorname{im} B=X_{\mathrm{c}} \text {. }
$$

It is called observable at infinity' in the sense of Verghese if

$$
\operatorname{kcr} E \cap \operatorname{kcr} C \cap A^{1}[\operatorname{im} E]=\{0\}
$$

and observable at infinity in the sense of Rosenbrock if

$$
\operatorname{kcr} E \cap \operatorname{kcr} C=\{0\} \text {. }
$$

The represcntation (3.11) is said to have no nondyncunic variables if

$$
A(k \operatorname{cr} E) \subset \operatorname{in} E \text {. }
$$

These are all properties that relate to the point at infinity. We note that, for representetions that satisfy (3.16), there is no difference betwecn controllability and reachability at infinity or between the two notions of obscrvability at infinity. In connection with the finitc modes, we shall need the following condition: a represcntation of the form (3.11) is said to have no finite unobservable modes if

$$
\operatorname{ranh}_{\mathbf{H}}\left(\begin{array}{c}
s E-A \\
C
\end{array}\right)=\operatorname{rank}_{\mathbf{H}(s)}\left(\begin{array}{c}
s E-A \\
C
\end{array}\right) \text { for all } s \in \mathbb{C} .
$$


In principle, a considerable number of descriptor representation types could be formed by taking combinations of the six conditions mentioned above. We shall consider just four types, which together secm to present a reasonable hicrarchy. The most unspecific type is the general descriptor form, for which the symbol $D$ has alrcady becn introduced. The symbol $D_{r i}$ will be used for the class of descriptor representations that are reachable at infinity. Descriptor represcntations that have no nondynamic variables and that are both controllable and obscrvable at infinity will be denoted as $D_{m i}$ representations ('minimal at infinity'). Finally, the class of $D_{\min }$ representations consists of the $D_{m i}$ representations that have no finite unobservable modes. It is shown in [34] that a descriptor representation is minimal under external cquivalence if and only if it belongs to this class.

\subsection{The road map}

To indicate the connections betwecn the somewhat vast number of representations introduced above, we shall now present a map. The following organizational principles have becn applicd:

- polynomial representations are on the left, first-order representations on the right;

representations that do not distinguish between inputs and outputs are in the middle, i/o representations are on the extremes;

more specific representations are higher up in the diagram than less specific oncs.

Morcover, arrows have becn used to indicate known transformation procedures (including the trivial oncs, which involve no transformation at all, and the very casy oncs, such as the transformation from AR to AR/MA). The organization of the diagram is such that arrows going up represent the heaviest computational loads. The result is shown in Fig. 1 bclow.

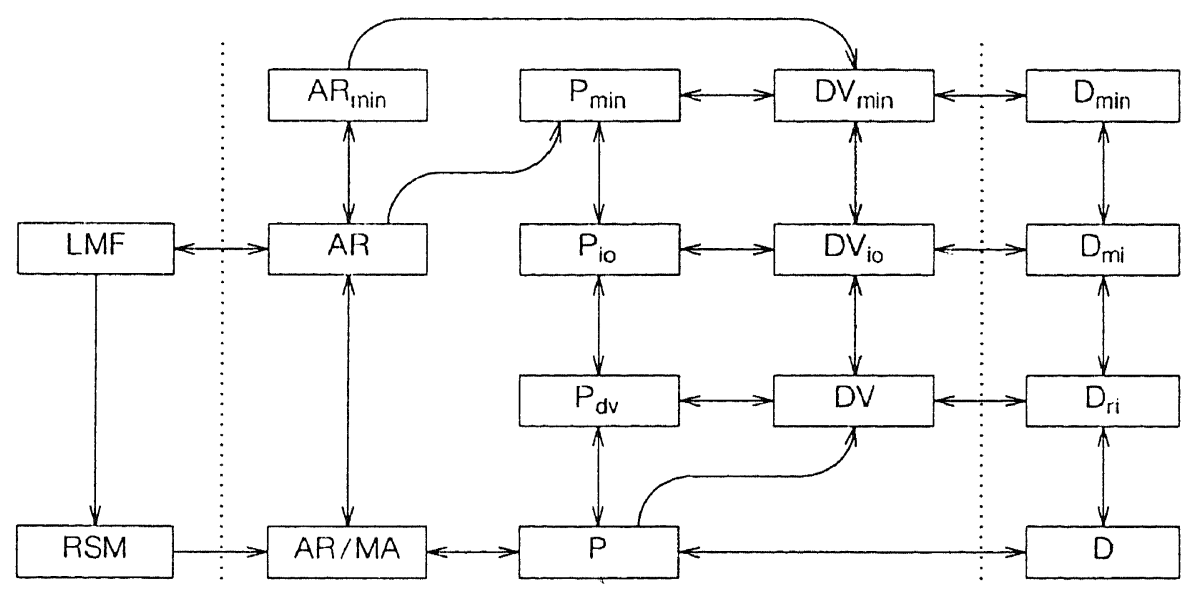

FiguR: 1. Representations and transformations of lincar systems.

The arrows going down in this diagram all correspond to trivial rewritings or rcinterpretations. For instance, an LMF representation is a special casc of an RSM representation, obtained by taking $V(s)=I$ and $W(s)=0$. The connection betwecn LMF and AR is also quitc clear. One gets from an RSM representation to an AR/MA representation simply by identifying the inputs with new internal variables. It is quite obvious how to transform the various types of 
DV representations to the $P$ representations on the same level, and vice versa. The transformation from $A R / M A$ to $P$ is by the standard trick of replacing higher-order derivatives by new variables. Most of the other transformations require more work, however, and some of the corresponding algorithms will be discussed below.

\subsection{Algorithms}

We start with the transition from an AR/MA representation to an AR representation. For this, we have the following procedure.

ALgorithm 1 Let an AR/MA representation be given by $(P(s), Q(s))$. For instance by the algorithm of reduction to Hcrmitc form ([39, pp. 32-33]; sce also [29, pp. 375-376] or [12, p. 34]), find a unimodular matrix $U(s)$ such that

$$
\left[\begin{array}{ll}
U_{11}(s) & U_{12}(s) \\
U_{21}(s) & U_{22}(s)
\end{array}\right]\left[\begin{array}{l}
P(s) \\
Q(s)
\end{array}\right]=\left[\begin{array}{c}
T(s) \\
0
\end{array}\right)
$$

where $T(s)$ has full iow rank. Let $R(s)$ be a maximal selection of independent rows from $U_{22}(s)$. Under thesc conditions, $R(s)$ gives an AR represcntation that is externally cquivalent to the AR/MA representation $(P(s), Q(s))$.

For a proof of this, sce [68, Prop. 3.3] or [33, Lemma 4.1]. The algorithm in [68] is actually based on the Smith form; from a computational point of view, this presents a considerable amount of overkill. In the algorithm given above, is is easy to sec that $U_{22}(s)$ will automatically have full row rank (so that we simply have $R(s)=U_{22}(s)$ ) when $P(s)$ has full row rank, which is a natural restriction to impose.

The passage from $A R$ to $A R_{\min }$ is just the reduction of a polynomial matrix to row proper form. The standard algorithm to do this is described for instance in [76, pp. 27-29] and in [29, p. 386]. This algorithm essentially requircs only operations on constant matrices, and the computational load involved is in gencral much lcss than in a transition from AR/MA to AR form.

The steps lcading from $P$ to $D V$, from $D V$ to $D V_{i 0}$, and from $D V_{i 0}$ to $D V_{\text {min }}$ are detailed in [56]. These steps can be 'lifted' to the level of P representations, and, in fact, it turns out that they can be derived quitc naturally in this context. We shall now explain this in some detail.

First, consider the transition from a gencral $P$ representations to the $P_{d v}$ representation. From the cquation $\sigma G \xi=F \xi$, it follows that any $\xi$-trajectory satisfying this cquation must belong to the subspace $F{ }^{1}[\mathrm{im} G]$. This implics, of coursc, that $G \xi$ bclongs to $G F{ }^{1}$ [im $\left.G\right]$. From that fact, it follows that any trajectory $\xi(\cdot)$ satisfying $\sigma G \xi=F \xi$ must actually bclong to the subspace $F^{-1}\left[G F^{-1}[\mathrm{im} G]\right]$, which obviously is contained in $F^{1}[\operatorname{im} G]$. We can go on in this way; a subspace recursion emerges which can be summarized as follows. Let the space on which $G$ and $F$ act be denoted by $Z$. Define

$$
Q^{0}=Z
$$

and

$$
Q^{k+1}=F^{-1} G Q^{k} .
$$

We have $Q^{k+1} \subset Q^{k}$ for all $k$, and so a limit must be reached after finitcly many (in fact, at most $\operatorname{dim} Z)$ steps. The limit subspace will be denoted by $Q^{*}(F, G)$ or simply by $Q^{*}$ if there is no risk of confusion. We arrive at the following algorithm to obtain a $P_{d v}$ representation from a $P$ representation. 
Algorithm 2 Let $(F, G, H ; Z, X, W)$ be a $\mathrm{P}$ represcntation. Compute the subspace $Q^{*}$ of $Z$ as the limit of the sequence of subspaces defined by (3.19-3.20). Take $\bar{Z}=Q^{*}, \bar{X}=: G Q^{*}$, and define $\tilde{F}, \tilde{G}$, and $\tilde{H}$ as the restrictions of the respective mappings to $\tilde{Z}$ and $\tilde{X}$. (Note that, by the definition of $Q^{*}, F$ docs indecd map $Q^{*}$ into $G Q^{*}$.) Under these conditions, a $P_{d v}$ representation that is equivalent to the original $P$ representation is given by $(\tilde{F}, \tilde{G}, \tilde{H} ; \tilde{Z}, \tilde{X}, W)$.

Next, we consider the transformation from a $P_{d v}$ to a $P_{i o}$ representation. Let $(F, G, H ; Z, X, W)$ bc a $\mathrm{P}_{\mathrm{dv}}$ representation, and suppose that $\left[G^{\top} H^{\top}\right]^{\top}$ is not injective. We can then split up the internal variable space $Z$ as $Z=Z_{1} \oplus Z_{2}$, where $Z_{2}=\operatorname{ker} G \cap \operatorname{ker} H$ is nonzero. With respect to this decomposition, writc $G=\left[\begin{array}{ll}G_{1} & 0\end{array}\right], F=\left[\begin{array}{ll}F_{1} & F_{2}\end{array}\right], H=\left[\begin{array}{ll}H_{1} & 0\end{array}\right]$. The cquations $\sigma G \xi=F \xi, w=H \xi$ then appear in the following form:

$$
\begin{aligned}
\sigma G_{1} \xi_{1} & =F_{1} \xi_{1}+F_{2} \xi_{2} \\
w^{\prime} & =H_{1} \xi_{1} .
\end{aligned}
$$

Since there are no restrictions on $\xi_{2}$, the above equations are cquivalent to

$$
\begin{aligned}
\sigma T G_{1} \xi_{1} & =T F_{1} \xi_{1} \\
w & =H_{1} \xi_{1}
\end{aligned}
$$

where $T$ is any map satisfying $\operatorname{ker} T=\operatorname{im} F_{2}$. It is natural to let $T$ be surjective, and we sec that the above transformation achicves a reduction of the dimension of the internal variable space and perhaps also a reduction of the dimension of the equation space. In more geometric terms, what we have done is the following. Define $S^{1}=\operatorname{kcr} G \cap \operatorname{ker} H$, and let $Z_{1}=Z / S^{1}, X_{1}=X / F S^{1}$. With these definitions, the factor mappings $G_{1}: Z_{1} \rightarrow X_{1}, F_{1}: Z_{1} \rightarrow X_{1}$, and $H_{1}: Z_{1} \rightarrow W$ are all well-defined, and the representation $\left(F_{1}, G_{1}, H_{1} ; Z_{1}, X_{1}, W\right)$ is equivalent to the original representation.

There is no guarantec that, after this step, the reduced representation is of the $P_{i 0}$ type, and in gencral the reduction will have to be repeated a number of times. For instance, the reduction in the second step is determincd by the subspace

$$
\begin{aligned}
\operatorname{kcr} G_{1} \cap \operatorname{kcr} H_{1} & =\left\{z \bmod S^{1} \mid G z \in F S^{1} \text { and } H z=0\right\} \\
& =\left(G{ }^{1} F S^{1} \cap \operatorname{kcr} H\right) \bmod S^{1} .
\end{aligned}
$$

The subspace recursion that emerges is the following:

$$
\begin{aligned}
& S^{0}=\{0\} \\
& S^{k+1}=G{ }^{1} F S^{k} \cap \operatorname{kcr} H .
\end{aligned}
$$

We have $S^{k+1} \supset S^{k}$ at cvery step, and so after finitcly many ( $\leqslant \operatorname{dim} Z$ ) steps a limit is reached. The limit subspace will be denoted by $S^{*}(F, G, H)$ or simply by $S^{*}$ if the context is clear. The algorithm to go from a $P_{d v}$ to a $P_{\text {io }}$ representation can now be formulated as follows.

Algorithim $3 \mathrm{Let}(F, G, H ; Z, X, W)$ be a $P_{d v}$ representation. Define the subspace $S^{*}$ of $Z$ as the limit of the sequence defium by (3.26-3.27). Define $\tilde{Z}=Z / S^{*}, \tilde{X}=Z / F S^{*}$. With these definitions, the factor mappings $\bar{G}: \tilde{Z} \rightarrow \tilde{X}, \tilde{F}: \tilde{Z} \rightarrow \tilde{X}$, and $\tilde{H}: \rightarrow W$ arc well-defined, and $(\tilde{F}, \tilde{G}, \tilde{H} ; \tilde{Z}, \tilde{X}, W)$ forms a $\mathrm{P}_{\text {io }}$ representation that is cquivalent to the original $\mathrm{P}_{\mathrm{dv}}$ representation.

The final transformation in this serics is the one that leads from $P_{i 0}$ to $P_{\min }$ representations. 
To achicve this reduction, we note that a redundancy in $\mathrm{P}_{\text {io }}$ descriptions is associated with subspaces $N$ of the internal variable space $Z$ that satisfy the two properties

$$
F N \subset G N
$$

and

$$
N \subset \operatorname{kcr} H \text {. }
$$

Indecd, if $N$ is a nonzero subspace having these propertics, then we can decompose the internal variable space $Z$ and the cquation space $X$ in such a way that $H=\left[\begin{array}{ll}H_{1} & 0\end{array}\right]$ and the mappings $G$ and $F$ takc the form

$$
G=\left[\begin{array}{cc}
G_{11} & 0 \\
0 & G_{22}
\end{array}\right], \quad F=\left[\begin{array}{cc}
F_{11} & 0 \\
F_{21} & F_{22}
\end{array}\right] .
$$

Of coursc, both $G_{11}$ and $G_{22}$ must bc surjectivc. The cquations become

$$
\begin{aligned}
\sigma G_{11} \xi_{1} & =F_{11} \xi_{1} \\
\sigma G_{22} \xi_{2} & =F_{21} \xi_{1}+F_{22} \xi_{2} \\
w & =H_{1} \xi_{1} .
\end{aligned}
$$

Becausc $G_{22}$ is surjective, the sccond equation can always be satisfied by a suitable choice of $\xi_{2}$; therefore, no constraint is imposed on $\xi_{1}$. This means that the second equation as well as the variablc $\xi_{2}$ may be removed without altering the external behavior. Spcaking geometrically, this means that we replace $Z$ by $\tilde{Z}=Z / N$ and $X$ by $\bar{X}=X / G N$, and that the mappings $F, G$ and $H$ are replaced by the respective factor mappings.

The reduction that is obtained in this way increases with $N$, and so we are interested in the largest clement of the set of subspaces satisfying both (3.28) and (3.29). (The fact that this set indecd has a largest clement follows from the fact that the set is closed under subspace addition.) Let us denote this largest element by $N^{*}(F, G, H)$. The question is, how to compute this subspace. The answer to this is provided by the following equality, which expresses perhaps the most basic result in the geonetric theory of lincar systems:

$$
N^{*}(F, G, H)=Q^{*}\left(\left[\begin{array}{c}
G \\
0
\end{array}\right],\left[\begin{array}{l}
F \\
H
\end{array}\right]\right) \text {. }
$$

Indecd, this gives us an algorithm to compute $N^{*}$. The proof of (3.34) is not difficult, and may cssentially be found in the standard refcrence [77, p. 91]. A considerable amount of translation of terms is necded, though, and the reader may find it casier to construct a direct proof. Rewriting the algorithm (3.19-3.20) a little bit to suit the special form which appears in (3.34), we finally obtain the following algorithm.

Algorirhm 4 Let $(F, G, H ; Z, X, W)$ be a $\mathrm{P}_{\mathrm{io}}$ representation. Define a sequence of subspaces of $Z$ by

$$
\begin{aligned}
& N^{0}=Z \\
& N^{k+1}=F \quad{ }^{1} G N^{k} \cap \mathrm{kcr} I I .
\end{aligned}
$$

Denote the limit subspace by $N^{*}$, and definc $\tilde{Z}=Z / N^{*}, \tilde{X}=X / G N^{*}$. With these definitions, the factor mappings $\tilde{G}: \tilde{Z} \rightarrow \tilde{X}, \tilde{F}: \tilde{Z} \rightarrow \tilde{X}$, and $\tilde{H}: \tilde{Z} \rightarrow W$ (corrcsponding to $G, F$, and $H$ 
respectively) are well-defincd, and the representation $(\tilde{F}, \tilde{G}, \tilde{H} ; \bar{Z}, \bar{X}, W)$ is a $\mathrm{P}_{\text {min }}$ representation that is equivalent to the given representation.

It has been proved in [56] (using somewhat different terminology) that this algorithm does indeed lcad to a minimal representation.

There is a trivial way to pass from a gencral pencil representation to a general descriptor representation. If $(F, G, H)$ is a $\mathrm{P}$ representation, and $H=\left[\begin{array}{ll}H_{y}^{\top} & H_{u}^{\top}\end{array}\right]^{\top}$ is the drcomposition of $H$ associated with a given partitioning of the external variables into inputs and outputs, then an equivalent $D$ representation is obviously given by

$$
\begin{gathered}
\sigma\left(\begin{array}{l}
G \\
0
\end{array}\right) \xi=\left(\begin{array}{c}
F \\
H_{u}
\end{array}\right) \xi+\left(\begin{array}{c}
0 \\
-I
\end{array}\right) u \\
y=H_{y} \xi .
\end{gathered}
$$

The main virtuc of this transformation is that it docsn't require computation. A transformation that does a better job at preserving minimality properties is given by the following algorithm.

Algokithm 5 Let $(F, G, H ; Z, X, W$ be a pencil representation, and let an i/o structure be given, so that $H=\left[\begin{array}{ll}H_{y}^{\dagger} & H_{u}^{\top}\end{array}\right]^{\top}$. Decompose the internal variable space $Z$ as $Z_{0} \oplus Z_{1} \oplus Z_{2}$ wherc $Z_{1}=\operatorname{kcr} G \cap \operatorname{kcr} H_{u}$, and $Z_{1} \oplus Z_{2}=\operatorname{ker} G$. Accordingly, writc

$$
\begin{aligned}
& G=\left[\begin{array}{lll}
G_{0} & 0 & 0
\end{array}\right], \quad F=\left[\begin{array}{lll}
F_{0} & F_{1} & F_{2}
\end{array}\right], \\
& H_{y^{\prime}}=\left[\begin{array}{lllll}
H_{y^{\prime} 0} & H_{y^{\prime} 1} & H_{y^{\prime} 2}
\end{array}\right], \quad H_{u}=\left[\begin{array}{llll}
H_{u} 0 & 0 & H_{u 2}
\end{array}\right] .
\end{aligned}
$$

The matrix $H_{u 2}$ has full column rank, and by renumbering the $u$-variables if necessary, we can writc

$$
H_{u 0}=\left(\begin{array}{l}
H_{10} \\
H_{20}
\end{array}\right], \quad H_{u 2}=\left(\begin{array}{l}
H_{12} \\
H_{22}
\end{array}\right)
$$

where $H_{22}$ is invertible (or cmpty, if $\operatorname{kcr} G \subset \operatorname{ker} H_{u}$ ). Define descriptor parameters by

$$
\begin{aligned}
& E=\left[\begin{array}{cc}
G_{0} & 0 \\
0 & 0
\end{array}\right], \quad A=\left[\begin{array}{cc}
F_{0}-F_{2} H_{22}{ }^{1} H_{20} & F_{1} \\
H_{10}-H_{12} H_{22} H_{20} & 0
\end{array}\right], \quad B=\left[\begin{array}{cc}
0 & F_{2} H_{22}{ }^{1} \\
-I & H_{12} H_{22}{ }^{1}
\end{array}\right], \\
& C=\left[\begin{array}{lll}
H_{y \cdot 0}-H_{y^{2}} H_{22}{ }^{1} H_{20} & H_{y \cdot 1}
\end{array}\right], \quad D=\left[\begin{array}{ll}
0 & H_{y \cdot 2} H_{22}{ }^{1} H_{20}
\end{array}\right] .
\end{aligned}
$$

These parametcrs definc a $D$ representation without nondynamic variables that is extcrnally cquivalent to the original $P$ representation. Morcover, if the given representation is of the $P_{d v}\left(P_{i o}\right.$, $\left.P_{\text {min }}\right)$ type, then the obtained representation is of the $D_{r i}\left(D_{m i}, D_{\min }\right)$ type.

The proofs of the statements above are given in [34]. At the ' $P_{d v}$ ' Icvel and higher, it might be said that the algorithm in fact uses the driving-variable representation as an intermediate step, so that the DV representations fit into the picture as shown in Fig. 1. The converse transformation is obtained as follows.

Algorithm 6 Let a $D_{1 i}$ representation be given by $(E, A, B, C, D)$ (so that $\left[\begin{array}{ll}E & B\end{array}\right]$ is surjective). Choose coordinates in such a way that

$$
E=\left[\begin{array}{ll}
I & 0 \\
0 & 0
\end{array}\right), \quad A=\left(\begin{array}{ll}
A_{11} & A_{12} \\
A_{21} & A_{22}
\end{array}\right), \quad B=\left[\begin{array}{ll}
B_{11} & B_{12} \\
B_{21} & B_{22}
\end{array}\right) \text {, }
$$




$$
C=\left[\begin{array}{ll}
C_{1} & C_{2}
\end{array}\right], \quad D=\left[\begin{array}{ll}
D_{1} & D_{2}
\end{array}\right]
$$

where $B_{22}$ is invertible. Define matrices $A^{\prime}, B^{\prime}, C^{\prime}$, and $D^{\prime}$ by

$$
\begin{aligned}
& \left(\begin{array}{cc}
s I-A^{\prime} & -B^{\prime} \\
C^{\prime} & D^{\prime}
\end{array}\right]= \\
& =\left(\begin{array}{cccc}
I & 0 & 0 & B_{12} B_{22}{ }^{1} \\
0 & I & 0 & -D_{2} B_{22}{ }^{1} \\
0 & 0 & I & 0 \\
0 & 0 & 0 & B_{22}{ }^{1}
\end{array}\right]\left[\begin{array}{ccc}
s I-A_{11} & -A_{12} & -B_{11} \\
C_{1} & C_{2} & D_{1} \\
0 & 0 & I \\
A_{21} & A_{22} & B_{21}
\end{array}\right) .
\end{aligned}
$$

The DV representation given by the four-tuple $\left(A^{\prime}, B^{\prime}, C^{\prime}, D^{\prime}\right)$ is externally equivalent to the given $D$ represcntation. Morcover, if the given descriptor representation is in the $D_{m i}\left(D_{\text {min }}\right)$ class, the resulting driving-variable representation is in the $D V_{i 0}\left(D V_{\min }\right)$ class.

For a proof of these statements, sec again [34]. More refined statements could be made; for instance, it is clear that to obtain a $D V_{\text {io }}$ representation from the algorithm above, it is sufficient that the $D$ representation we start with is reachable at infinity and obscrvable in the sense of Verghese.

The corresponding reduction to minimal form in the 'DV' branch can be thought of as a reformulation of the above in special coordinates. The details have becn worked out in [56]. The reductions takc a somewhat different form at the 'D' lcvel. Verghese [60] alrcady gave a simple algorithm to remove nondynamic variables. It has becn shown in [33] (Lemma 7.3 and Lemma 7.4) how to reduce a given descriptor representation in case it does not satisfy cither one of the conditions ' $\left[\begin{array}{ll}E & B\end{array} \mid \text { surjective' or ' } \mid E^{\top} \quad C^{\top}\right\rfloor^{\top}$ injectivc'. Clearly, by repcating thesc reduction steps if necessary, it is always possible to arrive at a situation in which these conditions are satisfied. The final passage to $D_{\min }$ comes down to removing the finite unobscrvable modes. This might for instance be donc via reduction to the Weicrstrass canonical form of the pencil $s E-A[26]$ followed by an application of the wcll-known procedure to remove unobservable modes in standard state space systems.

Finally, we conc to the transformation from $A R$ to $P_{\text {min }}$. This is essentially the Fuhrmann realization [23,24]. In [33], the transformation is given the following form.

Algoritrm 7 Let an AR representation be specificd by $R(s)$. Consider the following spaces of rational vector functions in a formal parametcr $\lambda(\pi$ denotes projection onto the proper rational functions, $W$ is the space of external variables, $k$ is the number of rows of $R(s))$ :

$$
\begin{aligned}
& X^{R}=\left\{w(\lambda) \in \lambda^{1} W\left[\left[\lambda^{-1}\right]\right] \mid \pi \quad R(\lambda) w^{\prime}(\lambda)=0\right\} \\
& \left.X_{R}=\left\{p(\lambda) \in \mathbb{R}^{k}[\lambda] \mid \exists w(\lambda) \in \lambda \quad{ }^{1} W\left[\mid \lambda \quad{ }^{1}\right]\right] \text { s.t. } p(\lambda)=R(\lambda) w^{\prime}(\lambda)\right\} \\
& N^{R}=\left\{w(\lambda) \in \lambda^{1} W\left[\left[{ }^{1}\right]\right] \mid R(\lambda) w(\lambda)=0\right\} .
\end{aligned}
$$

The following mappings ( $G$ and $F$ from $X^{R} / \lambda{ }^{1} N^{R}$ to $X_{R}, H$ from $X^{R} / \lambda{ }^{1} N^{R}$ to $W$ ) arc welldefined:

$$
\begin{aligned}
& G: w^{\prime}(\lambda) \bmod \lambda^{-1} N^{R} \mapsto R(\lambda) w^{\prime}(\lambda) \\
& F: w^{\prime}(\lambda) \bmod \lambda{ }^{1} N^{R} \mapsto R(\lambda) \pi\left(\lambda w^{\prime}(\lambda)\right)
\end{aligned}
$$




$$
H: w(\lambda) \bmod \lambda{ }^{1} N^{R} \mapsto w \cdot 1 .
$$

With these definitions, $(F, G, H)$ is a minimal pencil representation that is extcrnally cquivalent to the AR representation given by $R(s)$.

This version differs from Fuhrmann's original one in two respects. First, the resulting representation is given in pencil form rather than in standard state space form, so that it becomes possible to consider noncausal systems. (The Fuhrmann realization has been used before in a noncausal context $[14,75]$, but only by separating finite and infinite frequencies, and under the assumption that a transfer matrix exists.) Sccondly, the procedure is presented as one under external cquivalence, rather than as onc under transfer equivalence.

The transformation algorithm given above is abstract, and may be used very well in theoretical considerations. However, a more computational form can also be given (sec [33, §8]). This requires the given representation to be in $A R_{\min }$ form, and produces a representation in $D V_{\min }$ form, which cxplains the arrow between the corresponding boxes in our map of lincar system representations.

\section{THE FACTOR SYSTEM}

In [67], J. C. Willems has pointed out that there is a close connection between the notion of an 'almost controlled invariant subspace' and that of a 'factor system'. Before discussing the conncction, lct us bricfly recall what these two notions mean. To define the factor system, following the development in [65], let first $X$ be a finitc-dimensional vector space over $\mathbb{R}$. Also, let $A$ be a lincar mapping from $X$ into itsclf, and let $B$ be a lincar mapping ranging in $X$. The smooth system $\Sigma(A, B)$ on $X$ determined by $A$ and $B$ is the following set of $C^{\infty}$-functions from $\mathbb{R}$ into $X$ :

$$
\Sigma(A, B)=\left\{x(\cdot) \in C^{\infty}(\mathbb{R} ; X) \mid \dot{x}(t)-A x(t) \in \operatorname{im} B \text { for all } t\right\} .
$$

Let $\Sigma$ be a smooth system on $X$ and let $K$ be a subspace of $X$. Consider the following set of trajectorics on the factor space $X / K$ :

$$
\Sigma / K:=\{x(\cdot) \bmod K \mid x(\cdot) \in \Sigma\} .
$$

If this set of trajectorics is a smooth system on $X / K$, then $\Sigma / K$ is called the factor system determined by $\Sigma$ and $K$.

The notion of an almost controlled invariant subspace can be defined in the same context. So let us assume that a statc space $X$, a state mapping $A$, and an input mapping $B$ have becn given. A subspace $K$ is said to be almost controlled invariant [66] if for cvery $\epsilon>0$ and for cvery $x_{0}$ in $K$ there cxists a trajectory $x(\cdot)$ in $\Sigma(A, B)$ such that $x(0)=x_{0}$ and $\operatorname{dist}(x(t), K) \leqslant \epsilon$ for all $t \geqslant 0$. This concept has many applications in control theory, of which some are reviewed in the contribution by J. L. Willens to this volume.

Given a smooth system $\Sigma(A, B)$, onc would of coursc like to know under what conditions on $K$ the set $\Sigma / K$ is a factor system. It is claimed in [67] (Theorem A) that this will hold if and only if $K$ is almost controlled invariant. In the cited paper, only a sketchy proof is provided for the 'if' part of this statement, and the 'only if part is given without proof. Later on, a detailed proof of the 'if' part has becn provided in [59], but a complete proof of the reverse implication is still lacking in the litcrature. Our goal in this section is to provide a short proof of Theorem A of [67], using a result in [56]. This proof is cssentially based on manipulation of representations.

In the previous section, algorithms were presented for the removal of redundancies in pencil represcntations. In these algorithms, certain subspace recursions played a kcy rolc. Wc will also 
need thesc recursions below, as well as some related recursions which we will introduce now. To the sequence of subspaces $S^{k}$ defincd by (3.26-3.27), another scquence $\hat{S}^{k}$ can be related by

$$
\hat{S}^{k}=G^{1} F S^{k} \text {. }
$$

From (3.26-3.27), we sec that this sequence might also be defined by the recursion

$$
\begin{aligned}
& \hat{S}^{0}=\operatorname{ker} G \\
& \hat{S}^{k+1}=G{ }^{1} F\left[\hat{S}^{k} \cap \operatorname{kcr} H\right] .
\end{aligned}
$$

Denoting $\lim \hat{S}^{k}$ by $\hat{S}^{*}$, we also sce from the definitions that $S^{*}=\hat{S}^{*} \cap \operatorname{kcr} H$. It is furthermore uscful to introduce two subspace recursions that do not take place in the 'internal variable space' $Z$ but in the 'cquation space' $X$. The first of these is obtained if we define

$$
V^{k}=G N^{k} \text {. }
$$

The corresponding recursion is

$$
\begin{aligned}
& V^{0}=X \\
& V^{k+1}=G\left[\begin{array}{ll}
F & 1 \\
V^{k} \cap \operatorname{ker} H
\end{array}\right] .
\end{aligned}
$$

Similarly, we define

$$
T^{k}=G \hat{S}^{k}\left(=F S^{k}\right)
$$

with the corresponding recursion

$$
\begin{aligned}
& T^{0}=\{0\} \\
& T^{k+1}=F\left[G^{-1} T^{k} \cap \operatorname{kcr} H\right] .
\end{aligned}
$$

The limit subspaces resulting from these recursions will be denoted by $V^{*}$ and $T^{*}$, respectively.

The subspaces that have now becn introduced play a role in the charactcrization of some important system invariants in terms of the parameters in a $P_{d v}$ representation. If $(F, G, H ; Z, X, W)$ is a $\mathrm{P}_{\min }$ representation of a bchavior $\mathscr{B}$, we define the degree of this bchavior, to be denoted by $\operatorname{deg}(\mathscr{B})$, as $\operatorname{din} X$. Also, we define the order of $\mathscr{B}$, to be denoted by ord $(\mathscr{B})$, as $\operatorname{dim}$ $Z$. Since a $P_{\min }$ representation is determined up to isomorphisms of the internal variable space and the cquation space, the degrec and the order are clcarly independent of the choice of a particular $P_{\min }$ represcntation. There are of coursc many other cquivalcnt charactcrizations; for instance, the degrec is also equal to the sum of the row degrees of the matrix $R(s)$ in any $\mathrm{AR}_{\text {min }}$ representation of 5 , and to the dimension of the state space in any minimal statc space representation of any causal input-output bchavior that can be obtaincd from 96 by partitioning the extcrnal va riables in inputs and outputs. (For a catalog of such results, scc [69], Thm. 6.)

From the fact that the internal variable space in a $P_{\text {min }}$ representation is obtaincd from the internal variable space in a given $P_{d v}$ representation by successively factoring out the subspaces $S^{*}$ and $N^{*}$, it might be suspected that the degrec is given in terms of a Pov representation by $\operatorname{codim}\left(N^{*}+S^{*}\right)$. It has been cstablished in [56] (Thm.4.1) that this is indecd the casc. The relcvant result may be summarized, with some rephrasing, as follows.

Proposition 4.1 Let a behavior ô be given by a $\mathrm{P}$ dv representation $(F, G, I I ; Z, X, W)$. Define subspaces $S^{*}, N^{*}$, and $\hat{S}^{*}$ of $Z$, and subspaces $V^{*}$ and $T^{*}$ of $X$ by the recursions (3.26-3.27), (3.35-3.36), (4.4-4.5), (4.7-4.8), and (4.10-4.1I) respectively. We then have the following equalities: 


$$
\begin{aligned}
& \operatorname{deg}(\mathscr{B})=\operatorname{codim}\left(N^{*}+\hat{S}^{*}\right)=\operatorname{codim}\left(V^{*}+T^{*}\right) \\
& \operatorname{ard}(\mathscr{B})=\operatorname{codim}\left(N^{*}+S^{*}\right) .
\end{aligned}
$$

In case $\mathrm{ker} H$ contains $\mathrm{ker} G$, an alternative formula for the order is

$$
\operatorname{ord}(\mathscr{B})=\operatorname{codim}\left(V^{*}+\left(T^{*} \cap G(\operatorname{ker} H)\right)\right)
$$

Our next concern is to characterize a 'smooth system' in terms of system invariants. This is described in the following lemma.

LemMA 4.2 A linear time-invariant behavior $\mathscr{B}$ with external variable w has a representation in the form

$$
\begin{aligned}
\sigma x & =A x+B u \\
u^{\prime} & =x
\end{aligned}
$$

if and only if $\mathscr{B}$ has no static constraints (i. e. for all $w_{0} \in W$ there exists a $w \in \mathscr{B}$ such that $\left.w(0)=w_{0}\right)$, and $\operatorname{dim} W$ is equal to ord $(\mathscr{G})$.

Proor: Consider the 'if' part first. If $\operatorname{dim} W$ cquals ord $(\mathscr{B})$, then there exists a $\Gamma_{\ldots \text {...ii }}$ representation

$$
\begin{aligned}
\sigma G \xi & =F \xi \\
w & =H \xi
\end{aligned}
$$

in which the matrix $I I$ is square. From the requirement that 5 has no static constraints, it follows that $I$ must be nonsingular. Let $G^{\prime}$ denotc a right inverse of $G$, and let $\tilde{F}$ bc a mapping satisfying $\operatorname{im} \tilde{F}=\operatorname{ker}(F$. The equation (4.17) is then equivalent to

$$
\sigma \xi=G \cdot F \xi+F_{\eta}
$$

where $\eta$ is a ncw internal variablc. Using a nonsingular transformation of the $\xi$-variable, we can replace $/ /$ by the identity mapping. and then the desired form is reached.

I'or the 'only if' part, we first note that the bchavior defined by (4.15-4.16) has no static constraints. To determine the order of the bchavior represented by (4.15-4.16), we have to take into account the fact that this representation is not minimal. Let $T$ be any surjective mapping such that $\operatorname{ker} T=\operatorname{im} B ;$ then (4.15) is equivalent to

$$
\sigma T x=T A x \text {. }
$$

Morcover, the representation (4.20-4.16) is minimal and we sec that $\operatorname{dim} W$ is cqual to ord ( claimed.

To obtain the main result of this section we combine the above charactcrization of smooth systens, the result that gives the order in terms of a $P_{d v}$ representation, and a charactcrization of almost controlled invariant subspaces in terms of subspace recursions, taken from [66].

TH:orem 4.3 Let a smooth system $\mathrm{\Sigma}(A, B ; X)$ be given, and let $K$ be a subspace of $X$. Under these conditions, the set of trajectories of $\Sigma$ modulo $K, \Sigma / K$, is a smooth sy'stem if and only if $K$ is almost controlled inveriant.

P'Roor Let $C: X \rightarrow X / K$ be the factor mapping. Obviously, a representation of the behavior $\Sigma / K$ is given hy 


$$
\begin{aligned}
\sigma x & =A x+B u \\
w & =C x
\end{aligned}
$$

and so we have to find the conditions on $K$ under which this is a smooth system. First of all, note that the behavior $\Sigma / K$ can have no static constraints because otherwise the original system $\Sigma$ would also have static constraints, which we know is not the casc. Therefore, from the above Icmma and the proposition we sec that $\Sigma / K$ is a smooth system if and only if

$$
\operatorname{dim} X / K^{\prime}=\operatorname{codim}\left(V^{*}+\left(T^{*} \cap G(\operatorname{ker} H)\right)\right)
$$

where cverything is taken with respect to the parameters

$$
G=\left[\begin{array}{ll}
I & 0
\end{array}\right], \quad F=\left[\begin{array}{ll}
A & B
\end{array}\right], \quad H=\left[\begin{array}{ll}
C & 0
\end{array}\right] \text {. }
$$

(Notc that indeed $\mathrm{ker} / I$ contains $\mathrm{ker} G$, so that the above formula applics.) Rewriting the $V^{*}$ - and $T^{*}$-algorithms for the above special valucs of the $P_{d v}$ parameters whilc kecping in mind that $\operatorname{kcr} C=K$, wc obtain

$$
\begin{aligned}
& V^{0}=X \\
& V^{k+1}=K \cap A^{1}\left(V^{k}+\operatorname{im} B\right)
\end{aligned}
$$

and

$$
\begin{aligned}
& T^{0}=\{0\} \\
& T^{k ! 1}=A\left[T^{k} \cap K\right]+\operatorname{im} B .
\end{aligned}
$$

The algorithm (4.25-4.26) is recognized as the invariant subspace algorithm [77, p. 91]. If we definc $\hat{T}^{k}=T^{k} \cap K$, then the associated recursion is

$$
\begin{aligned}
& \hat{T}^{0}=\{0\} \\
& \hat{T}^{k+1}=K \cap\left(\hat{A} T^{k}+\mathrm{im} B\right)
\end{aligned}
$$

and this is recognized as the controllability subspace algorithm [77, p. 107], also known as the almost controllability' subspace algorithm [66]. Noting that $G[\operatorname{kcr} H]=\operatorname{kcr} C=K$, we sce that we always have

$$
K \supset V^{*}+\left(T^{*} \cap K\right)
$$

so that the condition (4.23) may be rewritten as

$$
K=V^{*}+\left(T^{*} \cap K\right)=V^{*}+\hat{T}^{*}
$$

But this is exactly the condition given in [66] for a subspace $K$ to be almost controlled invariant with respect to $(A, B)$. 


\section{ConClusions}

It should be emphasized that our 'road map' of system representations covers only a small arca in the large ficld of representation theory. We have only becn looking at the 'classical' form of external cquivalence, thereby excluding representations such as the matrix fractional form over the ring of proper and stable rational functions, which is onc of the main tools in the latest developments in control theory [21,43]. Also, there are many other classes of systems for which representation theory leads to uscful results. This of course includes the gencralizations to nonlinear and infinite-dimensional systems, but important new aspects also arise if one considers systems with particular propertics. A simple cxample is provided by the case of lincar systems with a Hamiltonian or a gradient structure, such as appear in the modeling of mechanical structures and clectrical networks. The problem of setting up state equations for such systems, starting from (higherorder) differential cquations and algebraic constraint equations, is in fact a classical one. For a treatment following lines as presented here, sce [57]. Of course, the Hamiltonian structure is important in the nonlincar context as well, and the problem of dealing with systems with mixed differential and algebraic equations comes up naturally for instance in setting up models for robots. For general nonlinear systems, the relations between systems of higher-order differential cquations on the onc hand and the standard state space form on the other have becn widely discussed; an carly reference is [22], and [15, 20,55, 58] provide a sample of recent contributions. It has been shown in [54], a nonlinear system of algebraic and differential equations in a DV-type form can be reduced to a minimal representation in standard state space form if and only if certain intcgrability conditions are satisficd. In the nonlincar case, the partitioning of external variables into inputs and outputs to obtain a causal $\mathrm{i} / \mathrm{o}$ structure is, in general, a local construction. This could be onc of the reasons for interest in a nonlinear version of the pencil form. Such a nonlinear jencil form might be specified by giving a submanifold of the tangent bundle of a manifold of internal variables, plus a mapping from that manifold to the manifold of external variables.

Representation theory for stochastic systems is a very well developed subject. The richer structure of stochastic systems allows for a varicty of representations, some of which are discussed in the contribution by J. II. van Schuppen to the present volume. However, it secms that not so much study has been made of questions concerning nonminimal representations, such as sometimes appear in modeling problens. As an example, consider an clectrical network with lincar elements containing some noisy resistors. Writing down network cquations in the usual way, onc could write down a representation in the form

$$
\begin{aligned}
G \dot{\xi} & =r \xi+J \eta \\
w & =H \xi
\end{aligned}
$$

where $\eta$ is 'white noisc', and $n$ ' represents the port variables. It requires proof to show that this can be rewritten in the standard form

$$
\begin{aligned}
& \dot{x}=A x+B u+N v \\
& y=C x+D u+M v
\end{aligned}
$$

where $v$ is white noisc, and $w$ has becn partitioned into inputs $u$ and outputs $y$. Representation of stochastic systens is also the subject of debate in cconometric circles (sec for instance [3, 17]).

Some aspects of the representation of infinite-dimensional lincar systems are discussed in the contribution of R. I . Curtain to this volume. A great deal of effort has been spent by the infinitcdimensional systems community on trying to fit into the standard $(A, B, C, D)$ framcwork 
cquations like the following one (the normalized string equation with forces and displacements at both ends as external variables):

$$
\begin{aligned}
\frac{\partial^{2}}{\partial t^{2}} \phi(x, t) & =\frac{\partial^{2}}{\partial x^{2}} \phi(x, t) \\
u^{\prime}(t) & =\left[\begin{array}{l}
\phi(0, t) \\
\phi(1, t) \\
\phi^{\prime}(0, t) \\
\phi^{\prime}(1, t)
\end{array}\right] .
\end{aligned}
$$

(The variable $x$ is used here as the spatial variable, and the prime denotes differentiation with respect to $x$.) Such an equation would fit morc naturally into representations of the pencil type. This advantage docsn't come without a price, however; whereas standard semigroup theory is available for writing down solutions of the cquations in $(A, B, C, D)$ form, another routc will have to be taken for systems in pencil form. Nevertheless, it would seem to be worth the effort to pursuc this dircetion. It should be noted that a representation which casily incorporatcs cquations like the string equation above has becn proposed by D. Salamon under the name 'boundary control systems' [53]; however, this class was introduced by Salamon for specific purposes, and the restrictions he imposes are consequently more severe than one would like to sec in a pencil representation.

The theory of system representations can be vicwed as a theory of modeling. Systemthcoretic idcas may be applied to modeling problems as wcll as to control problcms, and it may even be that some problems that are now considered as control problems will eventually be looked at rather as representation problems (model matching might fall in this category). In the process, it may be necessary to abandon some conventional wisdom. This paper has becn written as a tribute to Jan Willenss, one of the best abandoners of conventional thinking that I know.

\section{ACKNOWLEDGEMENT}

I would like to thank Margrect Kuijper, Henk Nijmeijer, and Arjan van der Schaft for their comments on an carlicr version of this paper.

\section{RETERENCES}

1. M.A. Aizerman (1949). On a problem concerning the stability in the large of dynamic systems. Usp. Mat. Nauk. 4, 187-188. (In Russian.)

2. B.D.O. Anderson, W. A. Coppel, D.J. Cullen (1985). Strong system cquivalence. J. Austral. Math. Soc. Ser. B 27, 194-222 (part I), 223-237 (part II).

3. M. AOKI (1988). Nonstationarity, cointegration, and crror correction in cconomic modeling. J. Econ. Dy'n. Contr. 12, 199-201.

4. J.D.Aplevich (1981). Time-domain input-output representations of lincar systems. Autoricutica 17, 509-522.

5. V.A. ARMENTANo (1984). The pencil $s E-A$ and controllability-obscrvability for gencralized lincar systcms: a gcometric approach. Proc. 23rd IEEE Conf. Dec. Contr., IEEE, Ncw York, 1507-1510.

6. J.S.Baras, R.W.Brockett, P.A.Fuhrmann (1974). Statc space models for infinitcdimensional systems. IEEE Trans. A utomat. Contr. AC-19, 693-700. 
7. R. Bellman, I.GlicksbuRg, O.Gross (1956). On the 'bang-bang' control problem. $Q$. Appl. Math. 14, 11-18.

8. H. Blomberg, R. YLinen (1983). Algebraic Theory for Multivariable Linear Systems, Ac. Press. I.ondon.

9. H.W. BodE (1945). Network Analysis and Feedback Amplifier Design, Van Nostrand, Princeton, $\mathrm{NJ}$.

10. H.W. Bode (1960). Fecdback - The history of an idea. Symposium on Active Networks and Feedback Systems (Polytechn. Inst. Brooklyn, April 19-21, 1960), Polytechnic Press, New York, 1-17. (Reprinted in R. Bellman, R. Kalaba (cds.), Selected Papers on Mathematical Trends in Control Theory, Dover, New York, 1964.)

11. D.W. Bushnw (1952). Differential Equations with a Discontinuous Forcing Term (Ph.D. thesis), Dept. of Math., Princeton Univ.

12. F. M. Callier, C. A. Desoer (19S2). Multivariable Feedback Sy'stems, Springer, New York.

13. J.D.CoBB (1984). Controllability, obscrvability, and duality in singular systcms. IEEE Trans. Automut. Contr: A C-29, 1076-1082.

14. G.Conte, A.M. Perdon (1982). Gencralized statc-space rcalizations for non-proper rational transfer functions. Syst. Contr. Lett. 1, 270-276.

15. P. E. Crouch, F. Lamnabhi-Lagarrigue (1988). State space rcalizations of nonlincar systems defined by input-output differential equations. A. BENSOUSSAN, J.L. Lions (cds.). Analysis and Optimization of System (Proc. INRIA Conf., Antibes, France, 1988), Lect. Nuus Contr. Inf. Sci. 111 , Springer, Berlin, 138-149.

16. C.A. Desoek, R.W. Liu, J. Murray, R. Saeks (1980). Fecdback system design: The fractional representation approach to analysis and synthesis. IEEE Trans. Automat. Contr: AC25, 399-412.

17. R. F. Engli, C. W.J. Grangle (1987). Co-integration and crror correction: Representation, cstimation, and testing. Econometrica 55, 251-276.

18. W. R. Evans (1948). Graphical analysis of control systcms. AIEE Trans. 67, 547-551.

19. P. M. G. Ferkeika (1987). On system equivalcnce. IEEE Trans. Automat. Contr. AC-32, 619-621.

20. M. Fluess (1988). Nonlincar control theory and differential algebra. C.I.BYRNeS, A. Kurzhanski (cds.). Modelling and Adaptive Control (Proc. IIASA Conf., Sopron, Hungary, 1986), Lcct. Notcs Contr. Inf. Sci. 105, Springer, Bcrlin, 134-145.

21. B. A. Francis (1987). A Course in $H_{\infty}$ Control Theory', Lect. Notes Contr. Inf. Sci. 88, Springer, Bcrlin.

22. M. I. Freedman, J.C.Willems (1978). Smooth representations of systems with diffcrentiated inputs. IEEE Trans. Automat. Contr: 23, 16-22.

23. P. A. Funkmann (1976). Algcbraic system thcory: an analyst's point of vicw. J. Franklin Inst. .301, 521-540.

24. P. A. Funrmann (1981). Linear Systems and Operators in Hilbert Space, McGraw-Hill, New York.

25. R. V.Gnmkrelidze (1958). Theory of time-optimal processes for lincar systems. Izvestia Akud. Nauk SSSR 22, 449-474. (In Russian.)

26. F. R. Gantmacher (1959). Matrix Theory (Part II), Chelsea, New York. (Russian original: 1954.)

27. E. Gilbert (1963). Controllability and obscrvability in multivariable control systems. SIAM J. Control 1, 128-151. 
28. B. L.Ho, R. E. Kalman (1966). Effective construction of lincar, state-variable models from input/output functions. Regelungstechnik 14, 545-548.

29. T. Kailath (1980). Linear Systems, Prentice-Hall, Englewood Cliffs, N. J.

30. R. E. Kalman (1963). Mathematical description of lincar systems. SIAM J. Control 1, $152-$ 192.

31. V. KuČERA (1974). Algcbraic theory of discretc optimal control for multivariable systcms. Kybernetika 10-12, 1-240. (Published in installments.)

32. V. KuCERA (1975). Algcbraic approach to discrete lincar control. IEEE Trans. Automat. Contr. 20, 116-120.

33. M.Kuijper, J.M.SChumacher (1989). Reulization of autoregressive equations in pencil and descriptor form, Report BS-R8903, CWI, Amsterdam.

34. M.KuiJPER, J.M. SCHumACHER (1989). Transformations under external equivalence for descriptor systens. (In preparation.)

35. A. M. Lerov (1953). Stability of control systems with two actuators. Prikl. Mat. Mekh. 4.

36. F. L. Lewis (1986). A survcy of lincar singular systems. Circuits Systems Signal Process. 5, 3-36.

37. D. G. Luenberger (1977). Dynamic cquations in descriptor form. IEEE Trans. Automat. Contr: AC-22, 312-321.

38. D. G. Luenberger (1978). Time-invariant descriptor systems. Automatica 14, 473-480.

39. C. C. MACDurFe (1956). The Theory of Matrices, Chelsca, Ncw York. (Reprint of original, 1933.)

40. A. G.J. MacFarlane (1979). The development of frequency-response methods in automatic control. IEEE Trans. Automat. Contr. AC-24, 250-265. (Reprinted in: A. G. J. MacFarlane (cd.), Frequency'-Response Methods in Control Systems, ILEE Press, New York, 1979, pp. 116.)

41. A. A. Markov (1894). On functions obtained by converting scrics into continued fractions. Zap. Petersburg Akad. Nauk. (In Russian. Reprinted in: A. A. Markov, Collected Works, Moscow, 1948, pp. 78-105.)

42. J. C. Maxwell (1868). On Govcrnors. Proc. Royal Soc. London 16, 270-283.

43. D. McFarlane, K. Glover (to appear). Robust Controller Design Using Normalized Coprime Factor Plant Descriptions.

44. B. McMillan (1952). Introduction to formal realizability theory. Bell Syst. Tech. J. 31, 217-279 (part I), 541-600 (part II).

45. N. Minorsky (1947). Introduction to Nonlinear Mechanics, Edwards Bros., Ann Arbor, Mich. (Originally published 1944-1946 as Restricted Reports by the David W. Taylor Model Basin, U.S. Navy.)

46. P.J.Nahin (1988). Oliver Heaviside: Sage in Solitude, ILEE Press, New York.

47. H. Nyquist (1932). Regencration theory. Bell Syst. Techn. J. 11, 126-147. (Reprinted in R. Blllman, R. Kalaba (eds.), Selected Papers on Mathematical Trends in Control Theory, Dover, New York, 1964, and in A.G.J. MacFarlane (cd.), Frequency-Response Methods in Control Systems, llilil Press, Ncw York, 1979.)

48. A.C. Pugh, G. E.lInYton, P. Fretwel.. (1983). Some transformations of matrix cquivalence arising from lincar systems theory. Proc. Automat. Contr. Conf. (San Francisco, CA).

49. A.C. Pugh, G. E. HAYton, P. Fretwell (1987). Transformations of matrix pencils and implications in lincar systems thcory. Int. J. Contr. 45, 529-548.

50. H. H. Rosenbrock (1968). Computation of minimal representations of a rational transfer- 
function matrix. Proc. IEE 115, 325-327.

51. H. H. Rosenbrock (1970). State Space and Multivariable Theory, Wilcy, New York.

52. H. H. Rosenirock (1974). Structural propertics of lincar dynamical systems. Int. J. Control 20, 191-202.

53. D. SAlAMON (1987). Infinite dimensional systems with unbounded control and obscrvation: a functional analytic approach. Trans. AMS 300, 383-431.

54. A.J. VAN DER SCHAFT (1987). On realization of nonlincar systems described by higher-order differential equations. Math. Syst. Th. 19, 239-275. (Correction: Math. Syst. Th. 20 (1987), 305-306.)

55. A.J. VAN DER SCHAFT (1989). Representing a nonlinear state space system as a set of higher-order differential cquations in the inputs and outputs. Syst. Contr. Lett. 12, 151-160.

56. J. M. SCHUMACHER (1988). Transformations of lincar systens under external equivalence. Lin. Alg. Appl. 102, 1-34.

57. J.M.SCHUMACHER (1988). State representations of linear systems with output constraints, Report OS-R8807, CWI, Amsterdam. (To appcar in MCSS.)

58. E. D. Sontag (1988). Bilincar realizability is equivalcnt to existence of a singular affine $\mathrm{I} / \mathrm{O}$ cquation. Syst. Contr. Lett. 11, 181-187.

59. H. L. Trentelman (1986). Almost Invariant Subspaces and High Gain Feedback, CWI Tract 29, CWI, Amstcrdam.

60. G. C. Verghese (1978). Infinite Frequency Behavior in Generalized Dynamical Systems (Ph. D. thesis), Information Systems Lab., Stanford Univ.

61. G. C. Verghese, B. Levy, T. Kailath (1981). A generalized state space for singular systems. IEEE Trans. Automat. Contr. AC-26, 811-831.

62. M.Vidyasagar (1984). The graph metric for unstable plants and robustness estimates for fccdback stability. IELE Trans. Automat. Contr. AC-29, 403-418.

63. N. Witener (1950). Comprehensive vicw of prediction theory. Proc. Int. Congr: Math., Cambridge, Mass., 1950, vol. 2, 308-321. (Reprinted in: P. MAsıNI (cd.), Norbert Wiener: Collected Works with Commentaries, MIT Press, Cambridge, Mass., 1981, 109-122.)

64. J. C. Willems (1979). System theoretic models for the analysis of physical systems. Ricerche di Automatica 10, 71-106.

65. J. C. Willems (1980). Topological classification and structural stability of lincar systems. $J$. Diff. Eq. 35, 306-318.

66. J. C. Willems (1980). Almost $A(\bmod B)$-invariant subspaccs. Astérisque 75-76, 239-248.

67. J.C.Willems (1981). Almost invariant subspaces: An approach to high gain fecdback design. Part I: Almost controlled invariant subspaces. IEEE Trans. Automat. Contr. AC-26, 235-252.

68. J.C.Willems (1983). Input-output and state-space represcntations of finite-dimensional lincar time-invariant systems. Lin. Alg. Appl. 50, 581-608.

69. J.C. Willems (1986). From time scrics to lincar system. Part I: Finite dimensional lincar time invariant systens. Automatica 22, 561-580.

70. J.C. Willems (1986). From time series to lincar system. Part II: Exact modelling. Automatica 22, 675-694.

71. J.C. Willems (1986). Deducing the input/output and the input/state/output structure from the cxternal bchavior. Proc. 25th IEEE Conf. Dec. Contr. (Athens, Grecce, Dec. 1986), IEEE P'ress, Ncw York, 1936-1937.

72. J.C. Willems (1987). From time scries to lincar systcm. Part III: Approximate modelling. 
Automatica 23,87-115.

73. J.C. Willems (1988). Models for dynamics. U. Kirchgraber, H.O. Walther (cds.). Dynamics Reported (Vol. 2), Wilcy/Teubncr, 171-269.

74. J.C. Willems, C. Heis (1986). Scattcring theory and approximation of lincar systems. C.I.Byrnes, A.Lindquist (cds.). Modelling, Identification and Robust Control, NorthHolland, Ansstcrdam, 397-411.

75. H.K. Wimmer (1981). The structure of nonsingular polynomial matrices. Math. Systems Theory 14, 367-379.

76. W.A. Wolovich (1974). Linear Multivariable Systems, Springer, Ncw York.

77. W.M.Wonham (1979). Linear Multivariable Control: a Geometric Approach (2nd cd.), Springer, Ncw York.

78. E. L. YIP, R. F. SINCOVEC (1981). Solvability, controllability, and observability of continuous descriptor systcms. IEEE Trans. Aut八mat. Contr. AC-26, 702-707.

79. D.C. Youla, J.J. Bonglokno, H. A.JABR (1976). Modern Wiencr-Hopf design of optimal controllcrs. Part 1: The singlc-input-output casc. IEEE Trans. Automat. Contr. 2I, 3-13.

80. D.C. Youla, J.J. Bonglorno, H. A.JABR (1976). Modern Wiener-Hopf design of optimal controllers. Part 2: The multivariable casc. IEEE Trans. Automat. Contr. 21, 319-338. 